\title{
Barreiras à Promoção da Criatividade no Ensino Fundamental ${ }^{1}$
}

\author{
Eunice M. L. Soriano de Alencar ${ }^{2}$ \\ Universidade Católica de Brasília \\ Denise de Souza Fleith \\ Universidade de Brasília
}

\begin{abstract}
RESUMO - O objetivo deste estudo é investigar a percepção de professores do ensino fundamental sobre barreiras que os dificultam a propiciar condições favoráveis ao desenvolvimento da capacidade criativa de seus alunos. Participaram do estudo 398 professores de 1aa a $4^{a}$ série do ensino fundamental, de escolas públicas e particulares localizadas no Plano Piloto de Brasília e em outras regiões administrativas do Distrito Federal, os quais responderam a uma checklist de barreiras à promoção da criatividade em sala de aula. As barreiras mais indicadas foram relativas ao aluno, como elevado número de alunos em sala de aula e alunos com dificuldades de aprendizagem. Um maior número de barreiras foi apontado por professores de escolas públicas localizadas em regiões administrativas do Distrito Federal distantes do Plano Piloto de Brasília e que lecionavam na 3ª série.
\end{abstract}

Palavras-chave: criatividade; ensino fundamental; barreiras à criatividade.

\section{Obstacles to the Promotion for Creativity in the Elementary School Level}

\begin{abstract}
The purpose of this study was to investigate elementary school teachers' perception of obstacles for the promotion of favorable conditions to the development of their students' creative capacity. The participants were $3981^{\text {st }}$ to $4^{\text {th }}$ grade elementary school teachers from public and private schools located in the Pilot Plan of Brasilia and other administrative regions of the Federal District, who completed a checklist of obstacles for the promotion of creativity in the classroom. The more frequent obstacles were related to the students, such as a great number of students in the classroom and students with learning difficulties. A greater number of obstacles were pointed out by teachers from public schools, from schools located far from the Pilot Plan of Brasilia and who taught to 3rd grade.
\end{abstract}

Key words: creativity; elementary school; obstacles to creativity.

A importância de se promover um ambiente propício ao desenvolvimento da criatividade tem sido reconhecida por um número crescente de educadores de distintos países. Tem sido lembrado que a instituição educacional não pode se restringir à transmissão apenas de conteúdos, técnicas e valores, uma vez que isso não é suficiente para garantir a adaptação e sucesso do indivíduo em um mundo marcado por mudanças que vêm ocorrendo em um ritmo exponencial e por um progresso sem precedentes. Vários autores, como Torrance (1995), Cropley (1997, 2005), Martínez (1997) e Alencar (2002; Alencar \& Fleith, 2003), consideram ainda que as experiências criativas de aprendizagem constituem-se em uma das vias para o bem-estar emocional, contribuindo positivamente para a qualidade de vida do indivíduo. Também tem sido ressaltado que a capacidade de pensar de forma criativa e inovadora, aliada à apresentação de atributos de personalidade que se associam à criatividade, ajuda o indivíduo a lidar com os desafios e complexidade típicos do atual momento da história. Por essa razão, promover a flexibilidade, a abertura ao novo, a habilidade de propor soluções inovadoras para problemas diversos e a coragem para enfrentar o inesperado deveria também fazer parte das metas a serem alcançadas pela escola em sua proposta pedagógica.

Este projeto contou com apoio do CNPq.

2 Endereço: Programa de Mestrado em Educação, Universidade Católica de Brasília. SGAN 916 Módulo B Asa Norte, Brasília, DF, Brasil 70790-160.E-mail: ealencar@pos.ucb.br
Ressalta-se que, apesar do reconhecimento crescente da necessidade de desenvolver no aluno a capacidade de pensar de forma criativa e de uma vasta literatura a respeito das características de ambientes educacionais que estimulam a expressão criativa, pesquisadores têm apontado falhas no sistema educacional no que diz respeito à promoção da criatividade nos diversos níveis de ensino (Cf. Alencar, 1995, 1999a, 1999b; Alencar \& Fleith, 2003; Cohen, 1997; Cole, Sugioka \& Yamagata-Lynch, 1999; Cropley, 1997; Furman, 1998; Necka, 1994; Sternberg, 1991, Sternberg \& Lubart, 1995; Toren, 1993, entre muitos outros). Furman (1998), por exemplo, assinalou que críticas têm sido feitas à educação da República da Eslováquia pela falta de criatividade no ensino e na situação de aprendizagem. Também Cole e colaboradores (1999) salientam que a maior parte dos ambientes educacionais não estimula e muitos deles bloqueiam a expressão criativa. Toren (1993) sinalizou a necessidade urgente de transformações nas práticas docentes, descrevendo um programa implementado em uma universidade da Holanda com o objetivo de desenvolver a capacidade criativa e reflexiva dos estudantes. Necka (1994), na Polônia, lembra que a escola típica é uma instituição conservadora, não estando preparada para propiciar condições necessárias para a expressão da criatividade. Cohen (1997), referindo-se à educação de Singapura, apresenta a constatação de autoridades educacionais daquele país de que muitos estudantes, embora competentes, têm dificuldades de apresentar pensamento original, por não ser 
essa modalidade de pensamento exercitada na escola. Cropley (1997), na Alemanha, salienta que as escolas e universidades estão produzindo um grande número de graduados, porém a maioria deles é treinada simplesmente para aplicar o já conhecido de maneira convencional. Nesse sentido, considera Cropley a grande necessidade de uma educação que encoraje a criatividade. Alencar (1995, 1999a, 2001; Alencar \& Fleith, 2003) e Wechsler (2001), no Brasil, lembram a prevalência de uma cultura de aprendizagem que estabelece limites muito abaixo das possibilidades do potencial para criar do ser humano, considerando que um currículo inflexível e rotina em sala de aula que pouco se altera, paralelamente à ênfase exagerada na reprodução do conhecimento, são fatores que restringem a expressão da capacidade de criar do aluno. Nos Estados Unidos, Sternberg (1991) observou que os professores estruturam suas práticas docentes de forma a não favorecer o surgimento de idéias criativas, chamando a atenção para a necessidade de o professor propiciar situações de aprendizagem que encorajem o aluno a visualizar novas soluções, enfatizar a flexibilidade no uso do conhecimento, além de instigar o aluno a experimentar e correr riscos. Também Renzulli (2005) lembra que a criatividade tem sido negligenciada, sendo necessários esforços renovados para se promover o desenvolvimento da criatividade produtiva nas instituições de ensino norte-americanas.

Não obstante essa análise feita por distintos especialistas da criatividade, constata-se escassez de estudos empíricos focalizando o que o professor considera como elementos que o dificultam a promover condições adequadas ao desenvolvimento da criatividade do aluno. Nota-se que, no Brasil, Carvalho e Alencar (2004) levantaram dados a esse respeito entre professores de Geografia de $5^{\underline{a}}$ a $8^{\underline{a}}$ séries e Vianna e Alencar (2006), entre tutores de cursos de educação on-line, constatando que as barreiras mais indicadas estavam relacionadas ao aluno. De forma similar, Mariani e Alencar (2005), em um estudo com professores de História que foram entrevistados a respeito de elementos que impedem ou limitam a expressão criativa em sua atividade docente, observaram que foram as características do aluno, como falta de motivação, participação, compromisso, agressividade e timidez, entre outras, o aspecto mais freqüentemente ressaltado.

Considerando o reduzido número de estudos e o fato de que a identificação dessas barreiras poderia ser útil na organização de um programa de preparação de professores e gestores para a implementação de uma cultura de criatividade na instituição escolar, desenvolveu-se o presente estudo que teve como objetivos investigar a percepção de professores do ensino fundamental sobre as barreiras que os dificultam propiciar condições favoráveis ao desenvolvimento da capacidade criativa de seus alunos, bem como identificar possíveis diferenças entre professores de distintas séries, tipo de escola (pública e particular) e localização da escola, nas barreiras apontadas.

\section{Método}

\section{Participantes}

Participaram do estudo 398 professores do ensino fundamental, sendo 18 (4,5\%) do gênero masculino e 378 (95,0\%) do gênero feminino (dois participantes deixaram de informar o gênero). Quanto à escolaridade, 61 (15,3\%) informaram ter o curso normal, $259(65,1 \%)$ o curso superior, $72(18,1 \%)$ especialização e $3(0,8 \%)$ o mestrado. Três participantes não indicaram a sua escolaridade. Entre os 334 que informaram ter cursado graduação e/ou pós-graduação, 308 indicaram o curso superior realizado. Entre estes, $222(55,8 \%)$ haviam cursado Pedagogia ou curso similar (como Escola Superior de Educação), 27 (6,8\%) Letras e $26(6,5 \%)$ Estudos Sociais. Os demais indicaram Educação Artística (7), Psicologia (6), Educação Física (5), Matemática (4), Biologia (2), Economia (1), Filosofia (1), Computação (1) ou dois ou mais cursos superiores (6).

Entre os 398 professores, 205 (51,5\%) lecionavam em escolas públicas e $190(47,7 \%)$ em escolas particulares. Três professores deixaram de informar o tipo de escola na qual trabalhavam. Cento e sessenta e quatro $(41,2 \%)$ desses professores lecionavam em escolas do Plano Piloto de Brasília, cuja população é predominantemente de status sócioeconômico médio, 176 (44,2\%) em escolas localizadas em outras regiões administrativas do Distrito Federal e 5 (1,3\%) em zona rural. Não foi possível identificar o local de trabalho nos questionários de $53(13,3 \%)$ professores.

É relevante informar que, no projeto original, previa-se a coleta de dados entre professores que estivessem lecionando

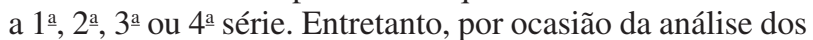
dados, constatou-se que mais de um quarto dos professores indicou que lecionava em mais de uma série entre as quatro primeiras do ensino fundamental, ou então que lecionava também na pré-escola ou em séries da segunda metade do ensino fundamental ou, ainda, no ensino médio, além de uma das quatro primeiras séries (veja Tabela 1). Nota-se que $22,4 \%$ dos professores lecionavam na $1^{\underline{a}}$ série, $18,3 \%$ na $2^{\underline{a}}$ série, $17,3 \%$ na $3^{\text {a }}$ série e $14,6 \%$ na $4^{\text {a }}$ série.

Tabela 1. Frequiência e porcentagem de professores que lecionavam em distintas séries.

\begin{tabular}{|c|c|c|}
\hline Série & $f$ & $\%$ \\
\hline $1 \mathrm{a}$ & 89 & 22,4 \\
\hline $2^{\mathrm{a}}$ & 73 & 18,3 \\
\hline $3^{\mathrm{a}}$ & 69 & 17,3 \\
\hline $4^{\mathrm{a}}$ & 58 & 14,6 \\
\hline $1^{\underline{a}}$ a $4^{\underline{a}}$ & 72 & 18,1 \\
\hline $1^{\mathrm{a}} \mathrm{a} 8^{\mathrm{a}}$ & 12 & 3,0 \\
\hline Pré a 4⿳亠丷厂 & 20 & 5,0 \\
\hline 1e série a Ensino Médio & 22 & 0,5 \\
\hline
\end{tabular}

Nota. Faltou a informação de três professores a respeito da série que lecionavam.

A média de idade dos participantes foi de 34,08 $(D P=8,39)$, variando de 18 a 64, com tempo médio de magistério de 11,36 anos $(D P=6,59)$, variando de um a 40 anos.

Instrumento e Procedimentos de Coleta de Dados

Utilizou-se uma checklist que incluía distintos fatores que poderiam ser considerados pelo professores como barreiras à promoção da criatividade em sala de aula, como, por exemplo, baixo incentivo para inovar a prática docente, falta de autonomia na forma de conduzir as atividades 
docentes, desinteresse do aluno pelo conteúdo ministrado, escassez de material didático disponível na escola, poucas oportunidades para discutir e trocar idéias com colegas sobre estratégias de ensino, falta de apoio institucional na implementação de projetos inovadores e falta de entusiasmo pela atividade docente, complementado com um conjunto de questões para levantamento de dados biográficos dos respondentes (gênero, idade, experiência docente, formação acadêmica) e de informações a respeito da série, tipo e local da escola em que lecionavam. Os professores foram instruídos a assinalar com um " $\mathrm{x}$ " os fatores considerados por eles barreiras ao desenvolvimento da criatividade em sala de aula. O instrumento foi construído com base em estudos teóricos e empíricos (Alencar, 1995, 2001; Alencar \& Fleith, 2003; Cropley, 1997; Fleith, 2000; Fishkin, Cramond \& Olszewski-Kubilius, 1999; Mariani \& Alencar, 2005; Morgan \& Foster, 1999; Smith, 1966; Torrance 1995). Esta checklist fazia parte de um questionário que incluía também uma escala sobre práticas docentes que favoreciam o desenvolvimento da criatividade do aluno, descrita em Alencar e Fleith (no prelo).

Antes de sua aplicação na amostra do presente estudo, a checklist passou pelo escrutínio de estudantes de graduação e pós-graduação que participavam de um grupo de pesquisa coordenado pelas autoras do presente estudo e por uma pesquisadora da área de criatividade no contexto educacional. Além disso, um estudo piloto foi conduzido com 16 professores das quatro primeiras séries do ensino fundamental, no sentido de se garantir a clareza das instruções e identificar possíveis mudanças na estrutura dos itens incluídos na checklist. Em seguida, foi realizado um contato inicial com a coordenação ou direção da escola para apresentação do projeto. Obtida a autorização da escola, foram agendados horários com os professores que aceitaram participar do estudo. Foi assegurado a eles o caráter confidencial das respostas fornecidas. Eles foram informados ainda de que os dados seriam analisados coletivamente. $\mathrm{O}$ instrumento foi respondido de forma individual e coletiva (em reuniões de coordenação de professores), sempre na presença do pesquisador (bolsistas de Iniciação Científica e outros estudantes treinados que integravam o grupo de pesquisa).

\section{Resultados}

Constatou-se, como pode ser observado na Tabela 2, que as barreiras mais indicadas pelos professores à promoção da criatividade em sala de aula foram: elevado número de alunos em sala de aula, alunos com dificuldades de aprendizagem em sala de aula e baixo reconhecimento do trabalho do professor (apontadas por $51,4 \%, 47,3 \%$ e $43,8 \%$ dos professores respectivamente). Três outras barreiras que tiveram expressiva indicação foram a extensão do programa a ser cumprido no decorrer do ano letivo, desinteresse do aluno pelo conteúdo ministrado e escassez de material didático disponível na escola (apontadas respectivamente por $38,2 \%, 38,5 \%$ e $38,5 \%$ dos docentes).

Por outro lado, as barreiras menos apontadas foram: insegurança para testar novas práticas docentes $(5,8 \%)$, falta de autonomia na forma de conduzir as atividades docentes $(7,1 \%)$ e falta de entusiasmo pela atividade docente $(8,9 \%)$.
Tabela 2. Barreiras indicadas pelos professores à promoção de condições adequadas ao desenvolvimento/expressão da criatividade do aluno (frequiência e porcentagem).

\begin{tabular}{|c|c|c|}
\hline Barreiras & $f$ & $\%$ \\
\hline Elevado número de alunos em sala de aula & 203 & 51,4 \\
\hline $\begin{array}{l}\text { Alunos com dificuldades de aprendizagem em } \\
\text { sala de aula }\end{array}$ & 187 & 47,3 \\
\hline Baixo reconhecimento do trabalho do professor & 173 & 43,8 \\
\hline Desinteresse do aluno pelo conteúdo ministrado & 152 & 38,5 \\
\hline Escassez de material didático disponível na escola & 152 & 38,5 \\
\hline $\begin{array}{l}\text { Extensão do programa a ser cumprido no decorrer } \\
\text { do ano letivo }\end{array}$ & 151 & 38,2 \\
\hline $\begin{array}{l}\text { Presença de alunos indisciplinados que perturbam } \\
\text { o trabalho docente }\end{array}$ & 141 & 35,7 \\
\hline $\begin{array}{l}\text { Poucas oportunidades para discutir e trocar idéias } \\
\text { com colegas sobre estratégias de ensino }\end{array}$ & 137 & 34,7 \\
\hline $\begin{array}{l}\text { Falta de apoio institucional na implementação de } \\
\text { projetos inovadores }\end{array}$ & 132 & 33,4 \\
\hline Qualidade dos livros didáticos adotados na escola & 122 & 30,9 \\
\hline Baixo incentivo para inovar a prática docente & 122 & 30,9 \\
\hline $\begin{array}{l}\text { Falta de oportunidade para realizar atividades fora } \\
\text { da sala de aula }\end{array}$ & 109 & 27,6 \\
\hline $\begin{array}{l}\text { Falta de orientação por parte da coordenação pedagógica } \\
\text { da escola no que diz respeito a como favorecer o } \\
\text { desenvolvimento da criatividade do aluno }\end{array}$ & 81 & 20,5 \\
\hline $\begin{array}{l}\text { Desconhecimento de práticas pedagógicas } \\
\text { que poderiam ser utilizadas para propiciar o } \\
\text { desenvolvimento da criatividade do aluno }\end{array}$ & 68 & 17,2 \\
\hline $\begin{array}{l}\text { Desconhecimento de textos (livros e/ou artigos) a } \\
\text { respeito de como implementar a criatividade em } \\
\text { sala de aula }\end{array}$ & 58 & 14,7 \\
\hline Falta de entusiasmo pela atividade docente & 35 & 8,9 \\
\hline $\begin{array}{l}\text { Falta de autonomia na forma de conduzir as } \\
\text { atividades docentes }\end{array}$ & 28 & 7,1 \\
\hline Insegurança para testar novas práticas pedagógicas & 23 & 5,8 \\
\hline
\end{tabular}

Na Tabela 3, são apresentadas a frequiência e a porcentagem de professores de escolas públicas e particulares que apontaram as distintas barreiras, bem como o valor do quiquadrado, teste estatístico utilizado para examinar possíveis diferenças entre a porcentagem de professores desses dois tipos de escolas que indicaram as referidas barreiras. Como pode ser observado na tabela, em apenas três itens não foram encontradas diferenças significativas entre o percentual desses dois grupos de professores, a saber: a) presença de alunos indisciplinados que perturbam o trabalho docente; $b$ ) poucas oportunidades para discutir e trocar idéias com colegas sobre estratégias de ensino; e c) falta de autonomia na forma de conduzir as atividades docentes. Nota-se que o único fator significativamente mais apontado por professores de escolas particulares $(46,3 \%)$, comparativamente aos docentes de escolas públicas $(30,7 \%)$, foi a extensão do programa a 
Tabela 3. Barreiras indicadas por professores de escolas públicas e particulares que os dificultam a promover condições adequadas ao desenvolvimento/ expressão da criatividade do aluno (freqüência, porcentagem e valor do qui-quadrado).

\begin{tabular}{|c|c|c|c|c|c|c|}
\hline \multirow{3}{*}{ Barreiras } & \multicolumn{4}{|c|}{ Escolas } & \multirow{3}{*}{$\chi^{2}$} & \multirow{3}{*}{$p$} \\
\hline & \multicolumn{2}{|c|}{ Pública } & \multicolumn{2}{|c|}{ Particular } & & \\
\hline & $f$ & $\%$ & $f$ & $\%$ & & \\
\hline Elevado número de alunos em sala de aula & 147 & 71,7 & 56 & 29,5 & 72,37 & 0,0001 \\
\hline Escassez de material didático disponível na escola & 127 & 62,0 & 25 & 13,2 & 101,02 & 0,0001 \\
\hline Baixo reconhecimento do trabalho do professor & 113 & 55,1 & 60 & 31,6 & 23,58 & 0,0001 \\
\hline Falta de apoio institucional na implementação de projetos inovadores & 106 & 51,7 & 26 & 13,7 & 65,64 & 0,0001 \\
\hline Desinteresse do aluno pelo conteúdo ministrado & 97 & 47,3 & 55 & 28,9 & 15,30 & 0,0001 \\
\hline Qualidade dos livros didáticos adotados na escola & 93 & 45,4 & 29 & 15,3 & 43,26 & 0,0001 \\
\hline Baixo incentivo para inovar a prática docente & 86 & 42,0 & 36 & 18,9 & 25,72 & 0,0001 \\
\hline Falta de oportunidade para realizar atividades fora da sala de aula & 74 & 36,1 & 35 & 18,4 & 16,60 & 0,0001 \\
\hline $\begin{array}{l}\text { Falta de orientação por parte da coordenação pedagógica da escola no que diz respeito a como favorecer } \\
\text { o desenvolvimento da criatividade do aluno }\end{array}$ & 68 & 33,2 & 13 & 6,8 & 43,21 & 0,0001 \\
\hline $\begin{array}{l}\text { Desconhecimento de práticas pedagógicas que poderiam ser utilizadas para propiciar o desenvolvimento } \\
\text { da criatividade do aluno }\end{array}$ & 52 & 25,4 & 16 & 8,4 & 21,00 & 0,0001 \\
\hline $\begin{array}{l}\text { Desconhecimento de textos (livros e/ou artigos) a respeito de como implementar a criatividade em } \\
\text { sala de aula }\end{array}$ & 48 & 23,4 & 10 & 5,3 & 27,08 & 0,0001 \\
\hline Alunos com dificuldades de aprendizagem em sala de aula & 113 & 55,1 & 74 & 38,9 & 11,60 & 0,003 \\
\hline Extensão do programa a ser cumprido no decorrer do ano letivo & 63 & 30,7 & 88 & 46,3 & 10,84 & 0,004 \\
\hline Insegurança para testar novas práticas pedagógicas & 19 & 9,3 & 4 & 2,1 & 10,23 & 0,006 \\
\hline Falta de entusiasmo pela atividade docente & 25 & 12,2 & 10 & 5,3 & 6,87 & 0,03 \\
\hline Presença de alunos indisciplinados que perturbam o trabalho docente & 73 & 35,6 & 68 & 35,8 & 0,93 & n.s. \\
\hline Poucas oportunidades para discutir e trocar idéias com colegas sobre estratégias de ensino & 73 & 35,6 & 64 & 33,7 & 1,12 & n.s. \\
\hline Falta de autonomia na forma de conduzir as atividades docentes & 16 & 7,8 & 12 & 6,3 & 1,28 & n.s. \\
\hline
\end{tabular}

ser cumprido no decorrer do ano letivo. Os demais foram apontados por um percentual significativamente maior de professores de escolas públicas.

Foram também comparadas as diferenças entre porcentagens de professores do Plano Piloto de Brasília e de outras regiões administrativas no que diz respeito às barreiras indicadas pelos docentes para promover condições adequadas ao desenvolvimento/expressão da criatividade do aluno (veja Tabela 4). Constatou-se que um percentual significativamente superior de professores de outras regiões administrativas do Distrito Federal comparativamente ao do Plano Piloto de Brasília indicou as seguintes barreiras: elevado número de alunos em sala de aula $(61,4 \%$ e $40,2 \%)$; desconhecimento de práticas pedagógicas que poderiam ser utilizadas para propiciar o desenvolvimento da criatividade do aluno $(22,2 \%$ e $10,4 \%)$; escassez de material didático disponível na escola $(53,4 \%$ e $22,6 \%)$; falta de orientação por parte da coordenação pedagógica da escola no que diz respeito a como favorecer o desenvolvimento da criatividade do aluno (30,7\% e 11,0\%); qualidade dos livros didáticos adotados na escola (40,3\% e 18,3\%); desconhecimento de textos (livros e/ou artigos) a respeito de como implementar a criatividade em sala de aula $(22,2 \%$ e $8,5 \%)$; falta de oportunidade para realizar atividades fora da sala de aula $(35,2 \%$ e $19,5 \%)$; e falta de apoio institucional na implementação de projetos inovadores $(40,3 \%$ e $25,6 \%)$. Por outro lado, constatou-se que um percentual significativamente superior de professores do Plano Piloto $(12,2 \%)$ apontou a falta de autonomia na forma de conduzir as atividades docentes, comparativamente àqueles de cidades satélites $(4,0 \%)$.

Foram ainda investigadas possíveis diferenças entre percentuais de professores das $1^{a}, 2 \stackrel{a}{\underline{a}}, 3^{\underline{a}}$ e $4^{\underline{a}}$ séries no que diz respeito às barreiras indicadas por eles (veja Tabela 5), tendo sido constatadas diferenças significativas entre os quatro grupos de professores nos seguintes itens:

- Desinteresse do aluno pelo conteúdo ministrado $\left(\chi^{2}=8,88 ; p=0,03\right)$;

- Poucas oportunidades para discutir e trocar idéias com colegas sobre estratégias de ensino $\left(\chi^{2}=17,54 ; p=0,001\right)$;

- Baixo incentivo para inovar a prática docente $\left(\chi^{2}=13,17\right.$; $p=0,004$ );

- Baixo reconhecimento do trabalho do professor $\left(\chi^{2}=10,36 ; p=0,016\right)$;

- Falta de orientação por parte da coordenação pedagógica da escola no que diz respeito a como favorecer o desenvolvimento da criatividade do aluno $\left(\chi^{2}=9,27 ; p=0,026\right)$.

As quatro primeiras barreiras foram indicadas por um percentual significativamente maior de professores da $3^{\underline{a}}$ série e a $5^{\underline{a}}$ por professores de $1^{\underline{a}}$ e $3^{\underline{a}}$ séries.

A checklist de barreiras à promoção de condições favoráveis à criatividade em sala de aula incluía também um espaço, na sua parte final, no qual o professor poderia acrescentar outras barrei- 
Tabela 4. Barreiras indicadas por professores do Plano Piloto e outras regiões administrativas do Distrito Federal que os dificultam a promover condições adequadas ao desenvolvimento/expressão da criatividade do aluno (frequiência, porcentagem e valor do qui-quadrado).

\begin{tabular}{|c|c|c|c|c|c|c|}
\hline \multirow{3}{*}{ Barreiras } & \multicolumn{4}{|c|}{ Localidade das Escolas } & \multirow{3}{*}{$\chi^{2}$} & \multirow{3}{*}{$p$} \\
\hline & \multicolumn{2}{|c|}{$\begin{array}{l}\text { Plano Piloto } \\
\text { de Brasília }\end{array}$} & \multicolumn{2}{|c|}{$\begin{array}{l}\text { Outras regiões } \\
\text { administrativas }\end{array}$} & & \\
\hline & $f$ & $\%$ & $f$ & $\%$ & & \\
\hline Elevado número de alunos em sala de aula & 66 & 40,2 & 108 & 61,4 & 15,15 & 0,0001 \\
\hline Escassez de material didático disponível na escola & 37 & 22,6 & 94 & 53,4 & 34,11 & 0,0001 \\
\hline Qualidade dos livros didáticos adotados na escola & 30 & 18,3 & 71 & 40,3 & 19,76 & 0,0001 \\
\hline $\begin{array}{l}\text { Falta de orientação por parte da coordenação pedagógica da escola no que diz respeito a como favorecer } \\
\text { o desenvolvimento da criatividade do aluno }\end{array}$ & 18 & 11,0 & 54 & 30,7 & 19,75 & 0,0001 \\
\hline Falta de oportunidade para realizar atividades fora da sala de aula & 32 & 19,5 & 62 & 35,2 & 10,48 & 0,001 \\
\hline $\begin{array}{l}\text { Desconhecimento de textos (livros e/ou artigos) a respeito de como implementar a criatividade } \\
\text { em sala de aula }\end{array}$ & 14 & 8,5 & 39 & 22,2 & 11,97 & 0,001 \\
\hline $\begin{array}{l}\text { Desconhecimento de práticas pedagógicas que poderiam ser utilizadas para propiciar o } \\
\text { desenvolvimento da criatividade do aluno }\end{array}$ & 17 & 10,4 & 39 & 22,2 & 8,58 & 0,003 \\
\hline Falta de apoio na implementação de projetos inovadores & 42 & 25,6 & 71 & 40,3 & 8,30 & 0,004 \\
\hline Falta de autonomia na forma de conduzir as atividades docentes & 20 & 12,2 & 7 & 4,0 & 7,84 & 0,005 \\
\hline Alunos com dificuldades de aprendizagem em sala de aula & 72 & 43,9 & 94 & 53,4 & 3,07 & n.s. \\
\hline Extensão do programa a ser cumprido no decorrer do ano letivo & 71 & 43,3 & 66 & 37,5 & 1,18 & n.s. \\
\hline Baixo reconhecimento do trabalho do professor & 70 & 42,7 & 80 & 45,5 & 0,26 & n.s. \\
\hline Desinteresse do aluno pelo conteúdo ministrado & 59 & 36,0 & 76 & 43,2 & 1,84 & n.s. \\
\hline Presença de alunos indisciplinados que perturbam o trabalho docente & 58 & 35,4 & 68 & 38,6 & 0,39 & n.s. \\
\hline Poucas oportunidades para discutir e trocar idéias com colegas sobre estratégias de ensino & 57 & 34,8 & 66 & 37,5 & 0,28 & n.s. \\
\hline Baixo incentivo para inovar a prática docente & 42 & 25,6 & 60 & 34,1 & 2,91 & n.s. \\
\hline Falta de entusiasmo pela atividade docente & 15 & 9,1 & 17 & 9,7 & 0,03 & n.s. \\
\hline Insegurança para testar novas práticas pedagógicas & 6 & 3,7 & 13 & 7,4 & 2,24 & n.s. \\
\hline
\end{tabular}

Tabela 5. Barreiras indicadas por professores de 1a à 4a séries que os dificultam a promover condições adequadas ao desenvolvimento/expressão da criatividade do aluno (freqüência, porcentagem e valor do qui-quadrado).

\begin{tabular}{|c|c|c|c|c|c|c|c|c|c|c|}
\hline \multirow{3}{*}{ Barreiras } & \multicolumn{8}{|c|}{ Séries que Lecionam } & \multirow{3}{*}{2} & \multirow{3}{*}{$p$} \\
\hline & \multicolumn{2}{|c|}{$1^{\mathrm{a}}$} & \multicolumn{2}{|c|}{$2^{\mathrm{a}}$} & \multicolumn{2}{|c|}{$3^{\mathrm{a}}$} & \multicolumn{2}{|c|}{$4^{\mathrm{a}}$} & & \\
\hline & $f$ & $\%$ & $f$ & $\%$ & $f$ & $\%$ & $f$ & $\%$ & & \\
\hline Poucas oportunidades para discutir e trocar idéias com colegas sobre estratégias de ensino & 24 & 27,0 & 22 & 30,1 & 39 & 56,5 & 18 & 31,0 & 17,54 & 0,001 \\
\hline Baixo incentivo para inovar a prática docente & 22 & 24,7 & 15 & 20,5 & 32 & 46,4 & 19 & 32,8 & 13,17 & 0,004 \\
\hline Baixo reconhecimento do trabalho do professor & 40 & 44,9 & 30 & 41,1 & 43 & 62,3 & 21 & 36,2 & 10,36 & 0,016 \\
\hline $\begin{array}{l}\text { Falta de orientação por parte da coordenação pedagógica da escola no que diz respeito } \\
\text { a como favorecer o desenvolvimento da criatividade do aluno }\end{array}$ & 27 & 30,3 & 9 & 12,3 & 20 & 29,0 & 11 & 19,0 & 9,27 & 0,026 \\
\hline Desinteresse do aluno pelo conteúdo ministrado & 27 & 30,3 & 26 & 35,6 & 36 & 52,2 & 26 & 44,8 & 8,88 & 0,03 \\
\hline $\begin{array}{l}\text { Desconhecimento de textos (livros e/ou artigos) a respeito de como implementar a } \\
\text { criatividade em sala de aula }\end{array}$ & 10 & 11,2 & 5 & 6,8 & 16 & 23,2 & 9 & 15,5 & 8,69 & 0,034 \\
\hline Insegurança para testar novas práticas pedagógicas & 6 & 6,7 & 6 & 8,2 & 3 & 4,3 & 2 & 3,4 & 1,75 & n.s. \\
\hline Falta de entusiasmo pela atividade docente & 5 & 5,6 & 6 & 8,2 & 9 & 13,0 & 2 & 3,4 & 4,87 & n.s. \\
\hline Falta de autonomia na forma de conduzir as atividades docentes & 3 & 3,4 & 6 & 8,2 & 6 & 8,7 & 3 & 5,2 & 4,57 & n.s. \\
\hline $\begin{array}{l}\text { Desconhecimento de práticas pedagógicas que poderiam ser utilizadas para propiciar o } \\
\text { desenvolvimento da criatividade do aluno }\end{array}$ & 13 & 14,6 & 12 & 16,4 & 14 & 20,3 & 9 & 15,5 & 0,98 & n.s. \\
\hline Falta de oportunidade para realizar atividades fora da sala de aula & 23 & 25,8 & 21 & 28,8 & 24 & 34,8 & 13 & 22,4 & 2,70 & n.s. \\
\hline Presença de alunos indisciplinados que perturbam o trabalho docente & 30 & 33,7 & 27 & 37,0 & 29 & 42,0 & 17 & 29,3 & 2,44 & n.s. \\
\hline Qualidade dos livros didáticos adotados na escola & 27 & 30,3 & 24 & 32,9 & 25 & 36,2 & 19 & 32,8 & 0,61 & n.s. \\
\hline Falta de apoio institucional na implementação de projetos inovadores & 28 & 31,5 & 23 & 31,5 & 26 & 37,7 & 21 & 36,2 & 1,001 & n.s. \\
\hline Extensão do programa a ser cumprido no decorrer do ano letivo & 32 & 36,0 & 24 & 32,9 & 25 & 36,2 & 23 & 39,7 & 0,65 & n.s. \\
\hline Escassez de material didático disponível na escola & 29 & 32,6 & 29 & 39,7 & 34 & 49,3 & 23 & 39,7 & 4,52 & n.s. \\
\hline Elevado número de alunos em sala de aula & 53 & 59,6 & 38 & 52,1 & 42 & 60,9 & 24 & 41,4 & 6,24 & n.s. \\
\hline Alunos com dificuldades de aprendizagem em sala de aula & 48 & 53,9 & 31 & 42,5 & 32 & 46,4 & 31 & 53,4 & 2,76 & n.s. \\
\hline
\end{tabular}


ras além daquelas apresentadas no instrumento. Do total de 396 participantes, nove utilizaram esse espaço para fazer comentários a respeito de seu trabalho, instituição de ensino ou Secretaria de Estado de Educação do Distrito Federal e 55 para apontar outras barreiras, as quais foram organizadas nas seguintes categorias:

1) Barreiras relacionadas ao aluno. Alunos imaturos e com diferentes tipos de problemas de aprendizagem ou comportamento foram apontados por três professores.

2) Barreiras relacionadas à família. Falta de apoio, envolvimento, interesse, incentivo, participação e acompanhamento dos familiares ao educando, além da baixa renda e desequilíbrio familiar, foram sinalizados por 20 participantes do estudo.

3) Ausência de espaço físico adequado, escassez de equipamentos, falta de cursos oferecidos pela instituição para capacitação docente, ausência de orientação no que diz respeito à metodologia a ser utilizada, qualidade e obrigatoriedade dos livros adotados e falta de professores para áreas específicas foram os principais aspectos relativos à escola, apontados por 30 professores.

4) Barreiras relacionadas ao professor. Baixa remuneração, falta de apoio e de reconhecimento social, trabalho cansativo e estressante, falta de tempo para estudo, planejamento, pesquisa e intercâmbio de idéias com colegas foram aspectos ressaltados por 10 professores.

5) Outras. Ausência de integração com a escola-parque (local onde o aluno de algumas escolas do Plano Piloto de Brasília tem aulas de artes e educação física), percepção negativa do professor pela comunidade, preço elevado de equipamento para projetos inovadores foram ressaltados por três professores.

\section{Discussão}

Observou-se que várias das barreiras apontadas por um maior número de professores eram mais diretamente relacionadas ao aluno, como, por exemplo, elevado número de alunos em sala de aula, alunos com dificuldade de aprendizagem e desinteresse do aluno pelo conteúdo ministrado. Tais resultados são similares àqueles obtidos por Carvalho e Alencar (2004), com uma amostra de professores de Geografia e por Vianna e Alencar (2006) com tutores de cursos de educação on-line. Tais barreiras refletem uma dificuldade por parte do professor em manter a atenção, interesse e participação do aluno, o que poderia ser um elemento facilitador à aprendizagem em sala de aula.

Outras barreiras também indicadas por percentual expressivo de professores foram o baixo reconhecimento do trabalho docente, extensão do programa a ser cumprido no decorrer do ano letivo e escassez de material disponível na escola; o primeiro relacionado à pouca valorização do professor na sociedade brasileira e os dois últimos ao currículo e condições materiais de instituições educacionais onde esses professores atuavam. É notório que a extensão do programa a ser cumprido ao longo do ano letivo foi discutida por Alencar $(1986,2004)$ e por Alencar e Fleith (2003). Lembram essas pesquisadoras que, em função do conteúdo e extensão do programa curricular a ser coberto, o tempo para o aluno desenvolver atividades exploratórias, testar idéias e fazer uso de formas divergentes de lidar com o conteúdo torna-se mais reduzido.

Insegurança para testar novas práticas pedagógicas, falta de autonomia na forma de conduzir as atividades docentes, desconhecimento de textos a respeito de como implementar a criatividade em sala de aula e falta de entusiasmo pela atividade docente foram as barreiras menos apontadas pelos professores. Os docentes se consideram, pois, preparados para propiciar as condições necessárias ao desenvolvimento e expressão da criatividade do aluno. Resultados similares a esses foram obtidos por Carvalho e Alencar (2004). Nota-se que apesar de os professores, de modo geral, apresentarem limitada formação pedagógica, com reduzido conhecimento teórico a respeito de criatividade, deixaram de apontar esse aspecto como barreira à promoção de condições adequadas ao cultivo da criatividade em sala de aula. Sinaliza-se ainda uma possível resistência do professor em ser avaliado, denotando dificuldade em admitir características pessoais como possíveis barreiras à promoção de condições adequadas à criatividade em sala de aula. É mais fácil deslocar para o aluno, a escola ou a sociedade os fatores que dificultam o seu trabalho docente no que diz respeito à promoção da criatividade em sala de aula.

Diferenças significativas entre professores de escolas públicas e particulares foram observadas na grande maioria das barreiras incluídas na checklist. Entre estas, apenas "a extensão do programa a ser cumprido no decorrer do ano letivo" foi apontada por um percentual significativamente superior de professores de escolas particulares e as demais por um percentual mais expressivo de professores da rede pública. Vale lembrar que resultados de um estudo conduzido anteriormente por Fleith e Alencar (2006) destacaram que alunos das escolas particulares apresentaram uma percepção mais positiva acerca do clima de sala de aula para criatividade do que os de escolas públicas. Ademais, em pesquisa desenvolvida por Fleith (2006), observou-se que alunos de escolas particulares apresentaram um desempenho superior em testes de criatividade quando comparados aos alunos que estudavam em escolas públicas.

Tais resultados sinalizam condições mais adversas percebidas pelos docentes da rede pública, o que deve refletir em sua atuação docente, clima em sala de aula e ainda no rendimento e motivação do aluno. Merece, pois, uma atenção especial por parte dos gestores das instituições públicas de ensino. Percebendo-se com pouco apoio e menor orientação, baixa valorização, desprovidos de maiores recursos para uma atuação eficaz, dificilmente os docentes sentir-se-ão realizados no plano pessoal e profissional. Esses mesmos fatores poderiam explicar as diferenças entre professores do Plano Piloto e demais regiões administrativas do Distrito Federal, tendo estes últimos apontado, mais do que os primeiros, condições adversas à promoção da criatividade em sala de aula. Por outro lado, o maior acompanhamento e cobrança por parte dos pais de alunos de escolas particulares no que diz respeito ao cumprimento do programa curricular, que parece ocorrer em escolas particulares, é uma possível explicação para o percentual mais expressivo de professores, dessa modalidade de escola, que consideraram a extensão do programa curricular um obstáculo à promoção da criatividade em sala de aula.

Foram os professores de 3 a série aqueles que em maior proporção indicaram barreiras em que diferenças significativas foram observadas. Esse resultado é difícil de ser explicado e merece ser investigado em estudos futuros.

\section{Conclusão}

Muitos são os aspectos que contribuem para o estabelecimento de um ambiente educacional que promove a criatividade. Tanto elementos relacionados ao currículo, ao aluno, ao professor, 
à escola quanto à sociedade, incluindo valores sócio-culturais, afetam a dinâmica em sala de aula, contribuindo em maior ou menor extensão para o florescimento de novas idéias e fortalecimento de atributos personológicos que se associam à criatividade. Martínez (2006) sintetiza essa idéia ao afirmar que:

O processo de produção de "algo novo", "com valor", é possível pelo interjogo de configurações subjetivas constituídas no sujeito no percurso de sua história de vida individual, da sua própria condição de sujeito e das configurações da subjetividade social, especialmente constituídas no espaço social em que o sujeito realiza sua ação (pp. 75-76).

O presente estudo limitou-se ao exame de barreiras percebidas pelos docentes à promoção da criatividade em sala de aula. Há outras variáveis que merecem ser objeto de estudo, como o grau de satisfação do professor no trabalho docente, a sua motivação para utilizar práticas docentes que promovem a criatividade, as práticas docentes que vêm implementando e a extensão em que as mesmas favorecem a expressão criativa. A opinião de gestores educacionais, coordenadores pedagógicos e alunos a respeito de práticas pedagógicas que os professores implementam ou deveriam implementar é também um aspecto que merece ser investigado.

Com relação às barreiras apontadas pelos professores, observa-se que muitas delas constituem-se em empecilhos, não apenas à promoção da criatividade mas também a uma aprendizagem efetiva. Elas merecem atenção dos gestores educacionais, dadas a importância e a necessidade de se garantir uma educação de boa qualidade, que leve em conta tanto a dimensão cognitiva quanto afetiva do aluno.

\section{Referências}

Alencar, E. M. L. S. (1986). Psicologia da criatividade. Porto Alegre: Artes Médicas.

Alencar, E. M. L. S. (1995). Criatividade. Brasília: Editora da Universidade de Brasília.

Alencar, E. M. L. S. (1999a, agosto). Mastering creativity for education in the 21stcentury. Palestra proferida no $13^{\text {th }}$ Biennial Conference, World Council for Gifted and Talented Children, Istambul, Turquia.

Alencar, E. M. L. S. (1999b). Educación para la creatividad. Educación, 10, 102-109.

Alencar, E. M. L. S. (2001). Criatividade e a educação do superdotado. Petrópolis: Vozes.

Alencar, E. M. L. S. (2002). O contexto educacional e sua influência na criatividade. Linhas Críticas, 8, 165-178.

Alencar, E. M. L. S. (2004). Como desenvolver o potencial criador (10 ed.). Petrópolis: Vozes.

Alencar, E. M. L. S. \& Fleith, D. S. (2003). Criatividade. Múltiplas perspectivas. Brasília: Editora UnB.

Alencar, E. M. L. S. \& Fleith, D. S. (no prelo). Escala de Práticas Pedagógicas para a Criatividade no Ensino Fundamental: desenvolvimento e validação. Interação.

Carvalho, O. \& Alencar, E. M. L. S. (2004). Elementos favorecedores e inibidores da criatividade na prática docente, segundo professores de Geografia. Psico, 35, 213-221.

Cohen, D. (1997, setembro). Singapore wants its universities to encourage more creativity. The Chronicle of Higher Education, 71-72.

Cole, D. G., Sugioka, H. L. \& Yamagata-Lynch, L. C. (1999). Supportive classroom environments for creativity in higher education. The Journal of Creative Behavior, 33, 277-292.
Cropley, A. J. (1997). Fostering creativity in the classroom: General principles. Em M. A. Runco (Org.), The creativity research handbook (pp. 83-114). Creskill: Hampton Press.

Cropley, A. J. (2005). Creativity in education \& learning. London: RoutledgeFalmer.

Fleith, D. S. (2000). Teacher and student perceptions of creativity in the classroom environment. Roeper Review, 22, 148-153.

Fleith, D. S. (2006). Características personológicas e fatores ambientais relacionados ao desenvolvimento da criatividade no contexto educacional (relatório de pesquisa). Brasília: Conselho Nacional de Desenvolvimento Científico e Tecnológico.

Fleith, D. S. \& Alencar, E. M. L. S. (2006). Percepção de alunos do ensino fundamental quanto ao clima de sala de aula para criatividade. Psicologia em Estudo, 11, 513-521.

Fishkin, A. S., Cramond, B. \& Olszewski-Kubilius, P. (1999). Investigating creativity in youth. Creskill: Hampton Press.

Furman, A. (1998). Teacher and pupil characteristics in the perception of the creativity of classroom climate. The Journal of Creative Behavior, 32, 258-275.

Mariani, M. F. M. \& Alencar, E. M. L. S. (2005). Criatividade e trabalho pedagógico segundo professores de História: limites e possibilidades. Psicologia Escolar e Educacional, 9, 27-36.

Martínez, A. M. (1997). Criatividade, personalidade e educação. São Paulo: Papirus.

Martínez, A. M. (2006). Criatividade no trabalho pedagógico e criatividade na aprendizagem: uma relação necessária? Em M.C.V.R. Tacca (Org.), Aprendizagem e trabalho pedagógico (pp. 69-94). Campinas: Alínea.

Morgan, S. \& Foster, J. (1999). Creativity in the classroom. Gifted Education International, 14, 29-43.

Necka, E. (1994, outubro). Teaching creativity in the classroom. General principles and some practical methods. Comunicação apresentada no Congresso Internacional Educação para o Futuro, São Paulo.

Renzulli, J. (2005). Neglecting creativity. Education Week, 24, 4 e 32.

Smith, J. A. (1966). Setting conditions for creative teaching in the elementary school. Boston: Allyn \& Bacon.

Sternberg, R. J. (1991). A theory of creativity. Trabalho apresentado no XIV School Psychology Association Colloquium. Braga, Portugal.

Sternberg, R. J. \& Lubart, T. I. (1995). Defying the crowd. Cultivating creativity in a culture of conformity. New York: The Free Press.

Toren, K. (1993). Transformations in management education. American Behavioral Scientist, 37, 112-120.

Torrance, E. P. (1995). Why fly? A philosophy of creativity. Norwood: Ablex.

Vianna, C. R. G. V. \& Alencar, E. M. L. S. (2006). Creativity and barriers to its expression in online education courses. Gifted Education International, 21, 54-62.

Wechsler, S. M. (2001). A educação criativa: possibilidades para descoberta. Em S. Castanho \& M. E. Castanho (Orgs.), Temas e textos em metodologia do ensino superior (pp. 165-170). Campinas: Papirus.

Recebido em 08.03.2007

Primeira decisão editorial em 01.07.2007

Versão final em 30.07.2007

Aceito em 05.10.2007 